\title{
Enhanced survival of Drosophila Akt1 hypomorphs during amino-acid starvation requires foxo
}

\begin{tabular}{|r|l|}
\hline Journal: & Genome \\
\hline Manuscript ID & gen-2015-0113 \\
\hline Manuscript Type: & Article \\
\hline Date Submitted by the Author: & 02-Sep-2015 \\
\hline Complete List of Authors: & $\begin{array}{l}\text { Slade, Jennifer; Memorial University of Newfoundland, Biology } \\
\text { Staveley, Brian; Memorial University of Newfoundland }\end{array}$ \\
\hline Keyword: & Drosophila melanogaster, starvation, Akt1, foxo \\
\hline \multicolumn{2}{|l}{} \\
\hline
\end{tabular}

\section{SCHOLARONE ${ }^{\text {m }}$ \\ Manuscripts}




\section{Title page}

2

3 Title: Enhanced survival of Drosophila Akt1 hypomorphs during amino-acid starvation requires foxo

4

5 Authors: Jennifer D. Slade ${ }^{1}$ and Brian E. Staveley ${ }^{1 *}$

6

71 Department of Biology, Memorial University of Newfoundland, 232 Elizabeth Avenue, St.

8 John's, Newfoundland and Labrador, A1B 3X9, Canada

9

10 Telephone: 1-709-864-4317

11

12 E-Mail: jdslade@mun.ca; bestave@mun.ca

13

$14{ }^{*}$ Corresponding Author 


\section{Abstract}

Disordered eating includes any pattern of irregular eating that may lead to either extreme weight loss or

18 obesity. The conserved insulin receptor signalling pathway acts to regulate energy balance and nutrient

19 intake, and its central component Akt1 and endpoint effector foxo are pivotal for survival during

20 nutritional stress. Recently generated $A k t 1$ hypomorphic mutant lines exhibit a moderate decrease in

21 lifespan when aged upon standard media, yet show a considerable increase in survival upon amino-acid

22 starvation media. While the loss of foxo function significantly reduces the survival response to amino-

23 acid starvation, a combination of these Akt1 hypomorphs and a null foxo mutation reveal a synergystic

24 and severe reduction in lifespan upon standard media, and an epistatic relationship when undergoing

25 amino-acid starvation. Evaluation of survivorship upon amino-acid starvation media of these double

26 mutants indicate a phenotype similar to the original foxo mutant demonstrating the role of foxo in this

27 Akt1 phenotype. These results indicate that the subtle manipulation of foxo through Akt1 can enhance

28 survival during adverse nutrient conditions to model the ability of individuals to tolerate nutrient

29 deprivation. Ultimately, we believe that a Drosophila model of disordered eating could generate new

30 avenues to develop potential therapies for related human conditions.

32 Key words: Drosophila melanogaster, starvation, Akt1, foxo 
Introduction

A number of eating disorders, including the medically diagnosable forms of anorexia and

bulimia, or any irregular eating patterns leading to extreme weight loss or gain, can be lifethreatening

37 (Neilson, 2001; Fairburn and Harrison, 2003). The psychiatric illness with the highest mortality rate is

anorexia, with $10 \%$ of diagnosed individuals dying within 10 years of the onset of the disease (Sullivan

2002). Irregular eating and periods of malnutrition may be common, as during the lifetime of most

organisms there is a fluctuation in the availability of nutrition. In order to deal with situations of low

41 nutrient availability, complex signalling cascades, such as the insulin receptor signalling pathway,

42 combine both the control of nutrient intake and the control of cell growth during development to

43 appropriately manage energy stores.

Drosophila melanogaster can serve as a simple animal model system to study the molecular

45 basis of starvation during nutrient deprivation. In Drosophila there are seven insulin-like peptides (IIps)

produced by 14 neurosecretory cells (Broeck 2001; Cao and Brown 2001; Ikeya et al., 2002). The insulin

47 receptor signalling (IRS) pathway in flies reduces the levels of trehalose in the hemolymph (Rion and

48 Kawecki 2007). Flies which lack Ilps develop into small adults with low fertility and metabolic defects

49 similar to mammalian diabetes including elevated sugar levels and initiation of the starvation response,

50 one aspect being lowered amount of triglycerides stored in the fat body (Zhang et al., 2009). The central

51 component of the insulin receptor signalling pathway, the serine/threonine kinase Akt1, is highly

52 conserved between mammals and Drosophila melanogaster (Scheid and Woodgett 2001; Franket et al.,

53 2003). In Drosophila, Akt1 is expressed throughout the organism during embryogenesis (Staveley et al.,

54 1998; Scanga et al., 2000; Cavaliere et al., 2005). A role for Akt1 in the control of cell growth and survival

55 is established as over-expression of $A k t 1$ in Drosophila leads to an increase in cell size, although there is

56 no effect on cell growth rates or division. Under-expression or loss of Akt1 can result in the production

57 of smaller animals or, if severe, in lethality (Kennedy et al., 1997; Staveley et al., 1998; Verdu et al., 
58 1999). The role of $A k t 1$ in cellular survival was suggested by its inhibition of several pro-apoptotic genes

59 (Kennedy et al., 1997; Nunez and del Peso 1998). As expected for a maternally expressed gene, Akt1

60 mutant females are sterile, and Drosophila Akt1 mutant germline clones undergo apoptosis (Staveley et

61 al., 1998). This demonstrates that the activities of the Akt1 kinase are of great importance to the

62 survival of the cell, and to the overall organism.

The negatively regulated downstream target of Akt1, the transcription factor foxo (Brunet et al.,

64 1999; Burgering and Medema 2003; Puig et al., 2003; Barthel et al., 2005; Puig and Tijan 2005), mediates

65 the transcriptional response of the insulin receptor pathway to fluctuating nutrient conditions.

66 As such, it controls a number of downstream targets involved in several important cellular functions.

67 These include control of metabolism, cell cycle regulation, DNA repair, apoptosis and protection against

68 oxidative stress (Burgering and Kops 2002; Barthel et al., 2005; Puig and Tijan 2005; Gershman et al.,

69 2007). Through these many functions, the transcription factor foxo can affect cell growth and survival.

70 Over-expression of foxo, such as its activation in the absence of insulin receptor signalling, results in

71 phenotypes that resemble starved larvae (Kramer et al., 2003). A reduced insulin receptor signalling

72 level is required for optimal survival during starvation, as over-expression of insulin receptor signalling

73 components leads to the inability of Drosophila to survive during nutritional stress (Britton et al., 2002).

74 Excess insulin receptor signalling results in a decrease in foxo activity, and loss of foxo function results in

75 a decrease in survivorship upon amino-acid starvation media (Kramer et al., 2008). These findings

76 suggest that insulin receptor signalling is involved in mediating the developmental response of larvae to

77 starvation, and leads to the conclusion that in the absence of adequate nutrition, insulin receptor

78 signalling is reduced, allowing foxo to enhance the transcription of downstream targets to aid in the

79 overall survival of the organism.

80 The majority of studies of starvation resistance in Drosophila focus on complete food

81 deprivation as opposed to reduction of any one major dietary component (Rion and Kawecki 2007). 
82 However, the lifespan of Drosophila under these conditions is extremely short, thereby limiting the

83 ability to observe any subtle differences in survival. The largest parts of a complete diet for Drosophila

84 include a carbohydrate source, such as sugar, and an amino-acid/ protein source, usually yeast. Flies

85 exposed to dietary restriction through a reduction of yeast alone, rather than sugar, are more sensitive

86 to starvation (Min and Tatar 2006). In addition, when survivorship of flies was compared from diets of

87 sugar alone to those with sugar and varying amounts of the protein casein, the addition of protein

88 improved the longevity of the flies. Age-specific mortality in Drosophila is recognized to be related to

89 dietary conditions (Good and Tatar 2001). Upon a full diet, including sufficient protein typically in the

90 form of yeast, survival of Drosophila is considered to be optimal. However, Drosophila exposed to a diet

91 lacking yeast show an increase in age-specific mortality, which decreases upon reintroduction of yeast.

92 Taking these findings into consideration, we believe a phenotype signifying starvation resistance on

93 amino-acid depleted media could be more enlightening than that same phenotype in other types of

94 starvation assays. We have characterized novel Akt1 mutants (Slade and Staveley 2015) that, upon

95 amino-acid starvation media, show an increased starvation resistance when compared to wild type

96 controls. When combined with a null foxo mutation, the novel Akt1 hypomorphs do not show the same

97 survivorship to suggest this phenotype is foxo dependent.

Materials and Methods

100

101

Generation and Source of Drosophila Strains and Culture

102

The initial P-element insertion line $r y^{506} P\{P Z\} A k t 1^{04226} / T M 3, r y^{R K}, S^{1}, \operatorname{Ser}^{1}\left(A k t 1^{04226}\right)$ was

104 obtained from the Bloomington Drosophila Stock Center (Perrimon et al., 1996; Spradling et al., 1999).

105 This line contains a P-element inserted within the 5' untranslated region of the Akt1 gene on the third 
106 chromosome. The control line $w ;+/+; P\left[F R T ; w^{+}\right]^{2 A} P\left[r y^{+} n e o R F R T\right]^{82 B} A k t 1^{+}\left(A k t 1^{+}\right)$was derived from

107 lines obtained from Dr. Norbert Perrimon, Harvard University. The novel mutants of $A k t 1^{52}, A k t 1^{57}$, and $108 A k t 1^{87}$, as previously described (Slade and Staveley 2015), were generated by imprecise excision of the P-

109 element via crossing to a line with a stable source of transposase, $P \Delta 2-3, r y^{+}$(Roberston et al., 1988).

110 These novel mutants are viable, developmentally delayed and reduced in size. The foxo null mutant line 111 w; foxo ${ }^{\text {W124x }}$ was obtained from Drs. E. Hafen and M. Junger (Junger et al., 2003) of the University of

112 Zurich. Wild-type Oregon R (OrR) stock was obtained from the Bloomington Drosophila Stock Center 113 and $w^{1118}$ was obtained from Dr. Howard Lipshitz from the University of Toronto. The stocks required for 114 transgenic replacement, w; arm-Gal4 and w; UAS-Akt1 were previously described (Staveley et al., 1998) 115 and complex lines were generated for each Akt1 allele (w; arm-Gal4; Akt1 ${ }^{m}$ and w; UAS-Akt1; Akt1 ${ }^{m}$ 116 where $m$ is the allele). Transgenic replacement studies were carried out by generating independent 117 lines of $w^{1118} ;$ UAS-Akt1 $1^{+}$CyO; Akt1 ${ }^{m} / T M 6 B$ and $w^{1118} ;$ arm-GAL4/CyO;Akt1 ${ }^{m} / T M 6 B$ where $m$ represents 118 each of the novel Akt1 mutant alleles. Crosses between these lines generated the critical class of $w^{1118}$; 119 UAS-Akt1 ${ }^{+} / a r m-G A L 4 ; A k t 1^{m} / A k t 1^{m}$ to be analyzed. Generation of flies bearing both the novel mutant 120 Akt1 alleles and a null foxo allele was performed via standard recombinant methods as previously 121 described (Slade and Staveley 2015). Stocks and crosses were maintained on a standard medium 122 containing cornmeal, molasses, yeast, agar and water. Routinely, stocks were kept at room temperature $123\left(22 \pm 2^{\circ} \mathrm{C}\right)$ while crosses and experiments were carried out at $25^{\circ} \mathrm{C}$.

Experiments were carried out on standard media containing cornmeal, molasses, yeast, agar and water at $25^{\circ} \mathrm{C}$. Adult heterozygous virgin females of $w ; F R T^{2 A} F R T^{82 B} A k t 1^{+}, w ; F R T^{2 A} F R T^{82 B} A k t 1^{04226}$ and each of the mutants were mated to heterozygous males of the same genotype. Several single vial 
130 matings of three to five females plus two males were made of each genotype which were transferred 131 onto new food every two days. A cohort of adult homozygous male flies were collected upon eclosion.

132 Only male flies were observed to avoid the effect of reproduction investment associated with female

133 flies. Approximately between 120 and 340 critical class males were aged per genotype, at a density of $\leq$

13420 flies per vial. Adults were kept on fresh media which was replenished every four to six days. Flies

135 were observed and scored every two days for presence of deceased adults. Flies were considered dead

136 when they did not display movement upon agitation. Longevity data was analyzed using the GraphPad

137 Prism 5.00 program. Survival curves were compared using the log-rank test, a statistical test that

138 compares the actual and expected number of failures (death) between survival curves at each individual

139 failure event. Significance was determined at 95\%, at a P-value less than or equal to 0.05.

Starvation Assay

Crosses as in the longevity assay were performed and homozygous males of the desired

144 phenotype were collected within 24 hours of eclosion. As in the longevity assay, male flies were 145 observed to avoid the effect of reproduction investment associated with female flies. Between one

146 hundred and nearly four hundred male flies were collected per genotype, and maintained in non-

147 crowded conditions by a maximum number of 20 flies per vial. Adults were aged on fresh amino-acid

148 starvation medium, consisting of $5 \%$ sucrose in phosphate buffered saline solution and $3 \%$ agar, and was

149 replenished every four to six days. Studies of survival upon the starvation media was carried out and

150 analyzed as described previously for the longevity assay. Flies were scored every two days for presence

151 of deceased adults. Adults were considered dead when they did not display movement upon agitation.

152 Results were analyzed using the GraphPad Prism 5.00 program. Survival curves were compared using

153 the log-rank test. This is a test statistic that compares the actual and expected number of failures 
154 (death) between survival curves at each individual failure event. Significance was determined at 95\%, at 155 a P-value less than or equal to 0.05 .

\section{Results}

Longevity assays comparing the lifespan of the mutant homozygotes to the wild-type controls indicate

162 there is a slight decrease in lifespan (Figure 1). The control had a median lifespan of 60 days, while $163 A k t 1^{52}$ had median lifespan of 52 days, and $A k t 1^{57}$ and $A k t 1^{87}$ both had a median lifespan of 57 days. This 164 corresponds to between a $13 \%$ and $16 \%$ decrease in lifespan.

Novel Akt1 mutants outlive controls on amino-acid starvation media

Starvation assays ageing mutant homozygotes and wild-type controls resulted in between $33 \%$ and $67 \%$

169 increase in survivorship of the $A k t 1$ hypomorphic mutants (Figure $2 \mathrm{~A}$ ). The $A k t 1^{+}$line, with the shortest

170 length of survival, has a median survivorship of 18 days. In comparison, the $A k t 1^{04226}$ line had a median

171 survival time of 24 days, $A k t 1^{57}$ survived for a median of 28 days, and both $A k t 1^{52}$ and $A k t 1^{87}$ have a

172 median time of survival of 30 days. When wild type $A k t 1$ was expressed under the control of the

173 armGal4 transgene in the genetic background of the Akt1 mutant homozygotes, the extension in survival 174 upon the starvation medium was suppressed (Figure 2B). This indicates the alteration of Akt1 activity in 175 the mutants is responsible for the extension in lifespan upon amino-acid starvation media. 
177 Combination of novel Akt1 hypomorphs and a null foxo mutation show a complex relationship

179 To determine if foxo was required for the observed longevity phenotypes of the Akt1 mutants,

180 Drosophila bearing mutations in both genes were generated and aged upon standard and amino-acid

181 starvation media. Lifespans of either the Akt1 mutants or the null foxo mutants upon standard media is

182 decreased, with median days of survival for the Akt1 mutants ranging between 52-57 days (Figure 1) and

183 the median lifespan of the null foxo mutants was 26 days (Figure $3 \mathrm{~A}$ ). The double mutant lines also

184 exhibited a decrease in lifespan when compared to the control with a median lifespan of 10 to 12 days

185 (Figure 3A). When starved of amino acids and protein, the null foxo mutants are sensitive with a median

186 lifespan of 12 days (Figure 3B). The novel Akt1 mutants have an extended lifespan with median survival

187 of 24 to 30 days (Figure $2 A$ ). The double mutant resembles the foxo mutants with a median survival by

188 day 14 (Figure 3B). This suggests that in the absence of foxo signalling, the Akt1 mutants do not outlive

189 the controls when starved of amino-acids.

190

Discussion

192

Ageing can be defined as the progressive degeneration of somatic tissues to the point that leads

194 to the eventual termination or death of the organism. Clues to the basis of the molecular control of

195 ageing was revealed in C. elegans when it was observed that certain mutants would undergo formation

196 of the dauer larvae stage, a type of starvation-induced developmental arrest, in the presence of free

197 access to food (Tatar 2004). In Drosophila, a similar diapause occurs with the manipulation of insulin

198 receptor pathway associated genes, and this diapause retards both ageing and growth. The underlying

199 mechanism may be instrumental in the increased longevities seen with mutants of some genes encoding

200 components of the insulin receptor signalling pathway. We have shown that hypomorphic Akt1 mutant 
201 homozygotes have a reduced lifespan when compared to controls with an 8 to 10 day difference in

202 median lifespan. While alterations to insulin receptor signalling components have shown an increase in

203 lifespan, the same is not true for these novel mutants. The Akt1 kinase is an important cell survival

204 protein, and expression of $A k t 1$ occurs throughout embryogenesis (Staveley et al., 1998). Null mutations

205 in Akt1 carried by germline clone females result in production of cuticle-deprived embryos and the

206 induction of ectopic apoptosis. Subtle reduction in Akt1 influenced activities could certainly impede

207 Drosophila development.

208

Interestingly, when aged upon amino-acid starvation media, these novel mutants show an

209 extension in lifespan. A method for enhancing starvation resistance is increasing energy stores such as

210 accumulated fats. A protein-poor diet in adult flies induces an increase in lipid reserves. Drosophila

211 deficient in insulin receptor signalling maintain an increase in lipid stores which may aid in starvation

212 resistance (Rion and Kawecki 2007). As these mutants are hypomorphs, similar to conditions of reduced

213 insulin receptor signalling, this might contribute to the extension in lifespan.

214 This phenotype may also be a result of a mechanism that shares some aspects with dauer

215 formation in C. elegans in response to low nutrients in which their growth is halted, and resumed again

216 once nutrients are replenished. Newly hatched Drosophila larvae require nutrients in order to increase

217 their body mass via replication of cells in mitotic tissues. In contrast, when larvae are hatched into

218 conditions of amino acid starvation, they live in a state of developmental arrest until nutrients become

219 available (Beadle et al., 1938; Kramer et al., 2003). When insulin receptor signalling is inhibited,

220 developmental arrest similar to that seen during starvation in first instar larvae occurs (Britton et al.,

221 2002). When larvae are amino acid starved, their overall growth is impeded. In previous studies,

222 dominant-negative mutations of $\mathrm{PI} 3 \mathrm{~K}$, and therefore inactivation of $\mathrm{Akt1}$, has been shown to result in

223 flies which phenocopy the effects of amino-acid starvation (Kramer et al., 2003). In addition, previous

224 studies of foxo's role during nutritional stress, by inducing ubiquitous expression of foxo in the first 
225 instar larvae, caused a complete arrest of growth, yet the larvae survived for several days (Junger et al., 226 2003; Kramer et al., 2003). As foxo is a significant downstream target of Akt1, it is possible that this is 227 responsible for the phenotypes we have observed.

228 Removing foxo activity from the Akt1 hypomorphs showed both synergistic and epistatic results.

229 Analysis of longevity upon standard media indicates that while both Akt1 and foxo may overlap one 230 another through sharing control over genes that regulate survival, reduction in activity or loss of both 231 severely impacts lifespan. This additive effect is evidently beyond the Akt1-foxo pathway and most likely 232 dependent upon one or more of the other downstream targets of either gene. Comparison of the Akt1 233 hypomorphs, null foxo mutants and the double mutants show that the double mutant lines much more 234 closely resemble the null foxo mutants. As the double mutants do not recapitulate the starvation 235 resistance of the Akt1 hypomorphs, this demonstrates the necessity of foxo in this process. Loss of foxo 236 has been shown to result in an increased sensitivity to starvation caused by low levels of amino acids 237 (Kramer et al., 2008). When nutrient levels are low, foxo activity is increased and upon return of 238 nutrients, foxo levels return to normal. Ectopic expression of Drosophila foxo leads to inhibition of 239 growth and generation of small adults. In addition, when there is an excess of foxo activity in larvae, 240 feeding behaviour is altered (Kramer et al., 2003). This highlights the importance of foxo in times of 241 nutritional stress, and taken together, these results show the importance of insulin receptor signalling 242 and foxo in the survival of organisms during malnutrition. This may be due to a number of the genes 243 that foxo transcriptionally activates. In mammalian tissue culture studies, foxo induces programmed cell 244 death, or apoptosis, through the withdrawal of cytokines, up-regulation of pro-apoptotic genes, such as 245 Bcl-2 family member Bim, cytochrome c release and caspase activation (Dijkers et al., 2002). In addition, 246 foxo induces the expression of genes associated with stresses including MnSOD and 4EBP (Zinke et al., 247 2002; Puig et al., 2003). An increase in MnSOD aids in the reduction of life threatening free radicals, 248 while induction of $4 E B P$ decreases protein synthesis, an unnecessary process during famine. The 
249 extended lifespan of $A k t 1$ mutants on amino-acid starvation media may act through foxo to induce the

250 expression of pro-survival genes.

251 Investigation of the ability of these novel Akt1 mutants to survive amino acid starvation may

252 provide an excellent basis to build an understanding of how organisms counteract the stress of an

253 inadequate diet. The ability to endure such conditions, if evolutionarily conserved, may be quite

254 relevant to the comprehension the basic biology of individuals living with eating disorders. Typically

255 patients do not respond well to psychological treatments while being nutritionally rehabilitated,

256 therefore the ability to sustain them until their psychological constraints can be alleviated could be very

257 beneficial. Developing Drosophila as a model to better understand the biological mechanisms

258 underpinning resistance to starvation may provide an approach that could eventually lead to the

259 development of therapies for these and other related human conditions.

260

261 List of abbreviations foxo: forkhead box subgroup " $O$ "; Ilp: insulin-like peptide; IRS: insulin receptor

262 signalling

263

264 Competing Interests

265 The authors declare that they have no competing interests.

267 Authors Contributions

268 JDS generated lines, performed the longevity and starvation assays, carried out the statistical analyses

269 and drafted the initial manuscript. BES generated mutants and lines, conceived and participated in the

270 design and supervision of the study and contributed significantly to the final draft of the manuscript. 
271 Both authors have read and approved the final manuscript.

\section{Animal Ethics}

274 This study was conducted under the approval of the Animal Care Committee of Memorial University of

275 Newfoundland as a Category of Invasiveness Level A protocol under the project title of "Genetic,

276 biochemical and molecular analysis of cell survival and cell death in Drosophila melanogaster" (protocol

277 number: 14-09-BS).

\section{Acknowledgments}

280 The authors would like to thank members of the Genomics and Proteomics facility at Memorial

281 University of Newfoundland for assistance with sequencing. Thanks also to Drs. Martin Junger and Ernst

282 Hafen for providing the foxo ${ }^{\text {W124X }}$ line, Dr. Howard Lipshitz for providing the $w^{1118}$ line, and to Dr. Norbert

283 Perrimon for providing the original $w^{1118} ; P\left[F R T ; w^{+}\right]^{2 A} P\left[r y^{+} n e o^{R} F R T\right]^{82 B}$ line. We thank Frankie Amanda

284 Slade for critical review of the manuscript. This project was funded by a Natural Sciences and

285 Engineering Research Council of Canada (NSERC) Post-Graduate Scholarship to JDS and NSERC Discovery

286 Grants to BES. JDS was also partially funded by a Department of Biology Teaching Assistantship and a

287 School of Graduate Studies Fellowship from Memorial University of Newfoundland.

\section{References}

Barthel, A., Schmoll, D., and Unterman, T.G. 2005. FoxO proteins in insulin action and metabolism. Trends Endocrinol Metab 16(4):233-34 
http://dx.doi.org/10.1016/j.tem.2005.03.010

PMid: 15860415

Beadle, G.W., Andreson, R.L., and Maxwell, J. 1938. A comparison of the diffusible substances concerned with eye colour development in Drosophila, Ephestia and Habrobracon. Proc Nat Acad Sci US 24(2):80-85

http://dx.doi.org/10.1073/pnas.24.2.80

Britton, J.S., Lockwood, W.K., Li., L., Cohen, S.M., and Edgar, B.A. 2002. Drosophila's insulin/PI3kinase pathway coordinates cellular metabolism with nutritional conditions. Dev Cell 2(2):239-49. http://dx.doi.org/10.1016/S1534-5807(02)00117-X

Broeck, J.V. 2001. Insect G Protein-coupled receptors and signal transduction. Arch Insect Biochem Physiol 48(1):1-12

http://dx.doi.org/10.1002/arch.1054

PMid: 11519072

Brunet, A., Bonni, A., Zigmond, M. J., Lin, M. Z., Juo, P., Hu, L. S., Anderson, M. J., Arden, K. C., Blenis, J. and Greenberg, M. E. 1999. Akt promotes cell survival by phosphorylating and inhibiting a Forkhead transcription factor. Cell 96, 857-68 http://dx.doi.org/10.1016/S0092-8674(00)80595-4

Burgering, B.M., and Kops, G.J. 2002. Cell cycle and death control: long live forkheads. Trends Biochem Sci 27(7):352-60.

http://dx.doi.org/10.1016/S0968-0004(02)02113-8

Burgering, B.M., and Medema, R.H. 2003. Decisions on life and death: FOXO Forkhead transcription factors are in command with PKB/Akt is off duty. J Leukoc Biol 73(6): 689-701. 
http://dx.doi.org/10.1189/jlb.1202629

PMid: 12773501

Cao, C. and Brown, M.R. 2001. Localiztion of an insulin-like peptide in brains of two flies. Cell Tissue Res 304(2):317-21

http://dx.doi.org/10.1007/s004410100367

PMid: 11396725

Cavaliere, V., Donati, A., Hsouna, A., Hsu, T. and Gargiulo, G. 2005. dAkt kinase controls follicle cell size during Drosophila oogenesis. Dev Dyn 232, 845-54.

http://dx.doi.org/10.1002/dvdy.20333

PMid:15712201 PMCid:PMC2265433

Dijkers, P. F., Birkenkamp, K. U., Lam, E. W., Thomas, N. S., Lammers, J. W., Koenderman, L. and Coffer, P. J. 2002. FKHR-L1 can act as a critical effector of cell death induced by cytokine withdrawal: protein kinase B-enhanced cell survival through maintenance of mitochondrial integrity. J Cell Biol 156, 531-42.

http://dx.doi.org/10.1083/jcb.200108084

PMid:11815629 PMCid:PMC2173339

Fairburn, C.G. and Harrison, P.J. 2003. Eating Disorders. Lancet 361:407-16

http://dx.doi.org/10.1016/S0140-6736(03)12378-1

Franke, T. F., Hornik, C. P., Segev, L., Shostak, G. A. and Sugimoto, C. 2003. PI3K/Akt and apoptosis: size matters. Oncogene 22, 8983-98.

http://dx.doi.org/10.1038/sj.onc.1207115

PMid: 14663477 
Gershman, B., Puig, O., Hang, L., Peitzcsh, R.M., Tatar, M., and Garofalo, R.S. 2007. Highresolution dynmaics of the transcriptional response to nutrition in Drosophila: a key role for dFOXO. Physiol Genomics 29(1):24-34.

http://dx.doi.org/10.1152/physiolgenomics.00061.2006

PMid: 17090700

Good, T.P. and Tatar, M. 2001. Age-specific mortality and reproduction respond to adult dietary restriction in Drosophila melanogaster. J Insect Physiol 47:1467-73. http://dx.doi.org/10.1016/S0022-1910(01)00138-X

Ikeya, T., Galic, M., Belawat, P., Nairz, K, Hafen, E. 2002. Nutrient-dependent expression of insulinlike peptides from neuroendorcrine cells in the CNS contributes to growth regulation in Drosophila. Curr Biol. 12(15):1293-300

http://dx.doi.org/10.1016/S0960-9822(02)01043-6

Junger, M.A., Rintelen, F., Stocker, H., Wasserman, J.D., Vegh, M., Radimerski, T., Greenberg, M.E. and Hafen, E. 2003. The Drosophila forkhead transcription factor FOXO mediates the reduction in cell number associated with reduced insulin signalling. J Biol 2(3):20.

http://dx.doi.org/10.1186/1475-4924-2-20

PMid:12908874 PMCid:PMC333403

Kennedy, S. G., Wagner, A. J., Conzen, S. D., Jordan, J., Bellacosa, A., Tsichlis, P. N. and Hay, N. 1997. The PI 3-kinase/Akt signalling pathway delivers an anti-apoptotic signal. Genes Dev 11, 701-13.

http://dx.doi.org/10.1101/gad.11.6.701

PMid: 9087425

Kramer, J. M., Davidge, J. T., Lockyer, J. M. and Staveley, B. E. 2003. Expression of Drosophila FOXO 
regulates growth and can phenocopy starvation. BMC Dev Biol 3, 5.

http://dx.doi.org/10.1186/1471-213X-3-5

PMid:12844367 PMCid:PMC183841

Kramer, J. M., Slade, J. D. and Staveley, B. E. 2008. foxo is required for resistance to amino acid starvation in Drosophila. Genome 51, 668-72.

http://dx.doi.org/10.1139/G08-047

PMid: 18650956

Min, K. J. and Tatar, M. 2006. Restriction of amino acids extends lifespan in Drosophila melanogaster. Mech Ageing Dev 127, 643-6.

http://dx.doi.org/10.1016/j.mad.2006.02.005

PMid: 16616772

Neilson, S. 2001. Epidemiology and mortality of eating disorders. Psychiatr Clin North Am 24:201-14 http://dx.doi.org/10.1016/S0193-953X(05)70217-3

Nunez, G. and del Peso, L. 1998. Linking extracellular survival signals and the apoptotic machinery. Curr Opin Neurobiol 8, 613-8.

http://dx.doi.org/10.1016/S0959-4388(98)80089-5

Perrimon, N., Lanjuin, A., Arnold, C., and Noll, E. 1996. Zygotic lethal mutations with maternal effect phenotypes in Drosophila melanogaster. II. Loci on the second and third chromosomes identified by P-element-induced mutations. Genetics 144(4):1681-92.

PMid:8978055 PMCid:PMC1207719

Puig, O. and Tijan, R. 2005. Transcriptional feedback control of insulin receptor by dFOXO/FOXO1. Genes \& Development 19(20):2435-46. 
http://dx.doi.org/10.1101/gad.1340505

PMid:16230533 PMCid:PMC1257398

Puig, O., Marr, M. T., Ruhf, M. L. and Tjian, R. 2003. Control of cell number by Drosophila FOXO: downstream and feedback regulation of the insulin receptor pathway. Genes Dev 17, 2006-20. http://dx.doi.org/10.1101/gad.1098703

PMid:12893776 PMCid:PMC196255

Rion, S. and Kawecki, T. J. 2007. Evolutionary biology of starvation resistance: what we have learned from Drosophila. J Evol Biol 20, 1655-64.

http://dx.doi.org/10.1111/j.1420-9101.2007.01405.x

PMid:17714282

Robertson, H.M., Preston, C.R., Phillis, R.W., Johnson-Schlitz, D.M., Benz, W.K., and Engels, W.R. 1988. A stable genomic source of P-element transposase in Drosophila melanogaster. Genetics 118(3):461-70.

PMid:2835286 PMCid:PMC1203300

Scanga, S. E., Ruel, L., Binari, R. C., Snow, B., Stambolic, V., Bouchard, D., Peters, M., Calvieri, B., Mak, T. W., Woodgett, J. R. et al. 2000. The conserved PI3'K/PTEN/Akt signalling pathway regulates both cell size and survival in Drosophila. Oncogene 19, 3971-7. http://dx.doi.org/10.1038/sj.onc.1203739

PMid: 10962553

Scheid, M. P. and Woodgett, J. R. 2001. PKB/AKT: functional insights from genetic models. Nat Rev Mol Cell Biol 2, 760-8.

http://dx.doi.org/10.1038/35096067

PMid: 11584303 
Slade, J.D. and Staveley, B.E. 2015. Compensatory growth in Drosophila Akt1 mutants. BMC Res Notes 8:77.

http://dx.doi.org/10.1186/s13104-015-1032-0

PMid:25889856 PMCid:PMC4372305

Spradling, A.C., Stern, D., Beaton, A., Rhem, E.J., Laverty, T., Mozden, N., Misra, S., and Rubin, G.M. 1999. The Berkley Drosophila Genome Project gene disruption project: Single P-element insertions mutating 25\% of vital Drosophila genes. Genetics 153(1): 135-77.

PMid:10471706 PMCid:PMC1460730

Staveley, B. E., Ruel, L., Jin, J., Stambolic, V., Mastronardi, F. G., Heitzler, P., Woodgett, J. R. and Manoukian, A. S. 1998. Genetic analysis of protein kinase B (AKT) in Drosophila. Curr Biol 8, 599602.

http://dx.doi.org/10.1016/S0960-9822(98)70231-3

Sullivan, P. 2002. Course and outcome of anorexia nervosa and bulimia nervosa. In Eating Disorders and Obesity. Edited by C.G. Fairburn and K.D. Brownell. New York, New York: Guilford. pp. 226232.

Tatar, M. 2004. The neuroendocrine regulation of Drosophila aging. Exp Gerontol 39, 1745-50. http://dx.doi.org/10.1016/j.exger.2004.06.024

PMid: 15582291

Verdu, J., Buratovich, M. A., Wilder, E. L. and Birnbaum, M. J. (1999). Cell-autonomous regulation of cell and organ growth in Drosophila by Akt/PKB. Nat Cell Biol 1, 500-6.

http://dx.doi.org/10.1038/70293

PMid: 10587646 
Zhang, H., Liu, J., Li, C. R., Momen, B., Kohanski, R. A. and Pick, L. 2009. Deletion of Drosophila insulin-like peptides causes growth defects and metabolic abnormalities. Proc Natl Acad Sci U S A $106,19617-22$.

http://dx.doi.org/10.1073/pnas.0905083106

PMid:19887630 PMCid:PMC2780814

Zinke, I., Schutz, C. S., Katzenberger, J. D., Bauer, M. and Pankratz, M. J. 2002. Nutrient control of gene expression in Drosophila: microarray analysis of starvation and sugar-dependent response. Embo J 21, 6162-73.

http://dx.doi.org/10.1093/emboj/cdf600

PMid:12426388 PMCid:PMC137192

290 
291

292

293

\section{Figure Legends}

\section{Figure 1: Longevity assay of novel Akt1 hypomorphs display a shortened lifespan when compared to} controls. Longevity is shown as percent survival ( $P<0.05$ as determined by log rank). The dotted line represents the median survival of the flies. The median lifespan of novel hypomorphic mutants falls between 8-10 days behind the wild type control. Full genotypes are $A k t 1^{+}: w ;+/+; P\left[F R T ; w^{+}\right]^{2 A} P\left[r y^{+} n e o R\right.$ $F R T]^{82 B} A k t 1^{+}(\mathrm{N}=148) ; A_{k t 1^{52}}: w ;+/+; P\left[F R T ; w^{+}\right]^{2 A} P\left[r y^{+} n e o R F R T\right]^{82 B} A k t 1^{52}$ (N=146); Akt1 ${ }^{57}: w ;+/+;$ $P\left[F R T ; w^{+}\right]^{2 A} P\left[r y^{+} n e o R \text { FRT }\right]^{82 B} A k t 1^{57}(\mathrm{~N}=167) ; A k t 1^{87}: w ;+/+; P\left[F R T ; w^{+}\right]^{2 A} P\left[r y^{+} n e o R\right.$ FRT ${ }^{82 B} A k t 1^{87}$ $(\mathrm{N}=133)$. Error bars represent the standard error of the mean.

\section{Figure 2: Amino-acid starvation survivorship assays of novel Akt1 hypomorphs indicate a long life} phenotype that is suppressed when wild type Akt1 is expressed. A: Amino-acid starvation survivorship of novel hypomorphs compared to a wild type control. Full genotypes are Akt1 $1^{+}: w ;+/+P\left[F R T ; w^{+}\right]^{2 A}$ $P\left[r y^{+} n e o R \text { FRT }\right]^{82 B} \operatorname{Akt1}^{+}(\mathrm{N}=237) ; \mathrm{Akt1}^{04226}: \mathrm{w} ;+++$; $\left[F R T ; w^{+}\right]^{2 A} P\left[r y^{+} n e o R F R T\right]^{82 B} \operatorname{Akt1}^{04226}(\mathrm{~N}=195)$; $\mathrm{Akt1}^{52}: w_{;}+/+; P\left[F R T ; w^{+}\right]^{2 A} P\left[r y^{+} n e o R \text { FRT }\right]^{82 B} A k t 1^{52}$ (N=198); Akt1 ${ }^{57}: w ;+/+P\left[F R T ; w^{+}\right]^{2 A} P\left[r y^{+} n e o R\right.$ $F R T]^{82 B} A k t 1^{57}(\mathrm{~N}=206) ; \mathrm{Akt}^{87}: w ;+/+; P\left[F R T ; w^{+}\right]^{2 A} P\left[r y^{+} n e o R F R T\right]^{82 B} A k t 1^{87}$ (N=204). B: Amino-acid starvation survivorship of hypomorphs with background expression of wild type Akt1+. Full genotypes are Akt1 ${ }^{+}: w ; \operatorname{arm}-G A L 4 / U A S A k t 1^{+} ; P\left[F R T ; w^{+}\right]^{2 A} P\left[r y^{+} n e o R\right.$ FRT ${ }^{82 B} A k t 1^{+}(\mathrm{N}=256) ; A k t 1^{04226}: w ;$

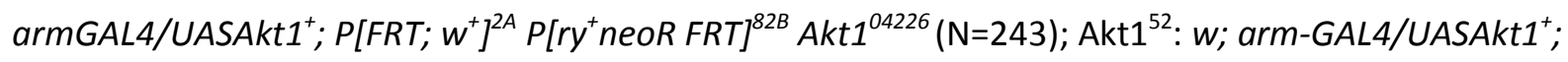
$P\left[F R T ; w^{+}\right]^{2 A} P\left[r y^{+} n e o R \text { FRT }\right]^{82 B} A k t 1^{52}(\mathrm{~N}=254) ; A k t 1^{57}: w ; \operatorname{arm}-G A L 4 / U A S A k t 1^{+} ; P\left[F R T ; w^{+}\right]^{2 A} P\left[r y^{+} n e o R\right.$ FRT ${ }^{82 B} A k t 1^{57}$ (N=225); Akt1 ${ }^{87}: w ;$ arm-GAL4/UASAkt1 $1^{+}$P $\left[F R T ; w^{+}\right]^{2 A} P\left[r y^{+} n e o R F R T\right]^{82 B}$ Akt1 $^{87}(\mathrm{~N}=235)$. Survivorship is shown as percent survival ( $P<0.05$ as determined by log rank). The dotted line represents the median survival of the flies. Error bars represent the standard error of the mean. 
316 Figure 3: Longevity and amino-acid starvation survivorship assays of Drosophila bearing both novel

317 Akt1 and a null foxo mutations: a synergistic effect upon standard media and an epistatic relationship

318 when starved of amino-acids. A: Longevity assay of double and single mutants. B: Amino-acid

319 starvation survivorship assay of single and double mutants. Full genotypes are Akt1 ${ }^{+}: w ;+/+P[F R T$;

$\left.320 w^{+}\right]^{2 A} P\left[r y^{+} n e o R F R T\right]^{82 B} A k t 1^{+}(\mathrm{N}=149$ or 237$) ; A k t 1^{57}: w ;++; P\left[F R T ; w^{+}\right]^{2 A} P\left[r y^{+} n e o R F R T\right]^{82 B} A k t 1^{57}(\mathrm{~N}=166$

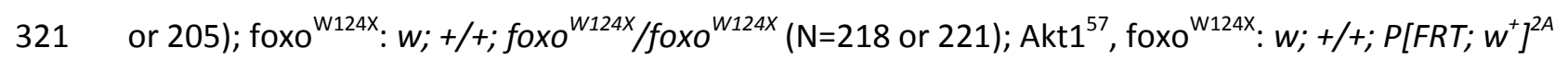

$322 P\left[r y^{+} \text {neoR FRT }\right]^{82 B} A k t 1^{57} /$ foxo ${ }^{W 124 x}$ ( $\mathrm{N}=120$ or 97$)$. Survivorship is shown as percent survival $(\mathrm{P}<0.05$ as

323 determined by log rank). The dotted line represents the median survival of the flies. Error bars represent

324 the standard error of the mean.

325 


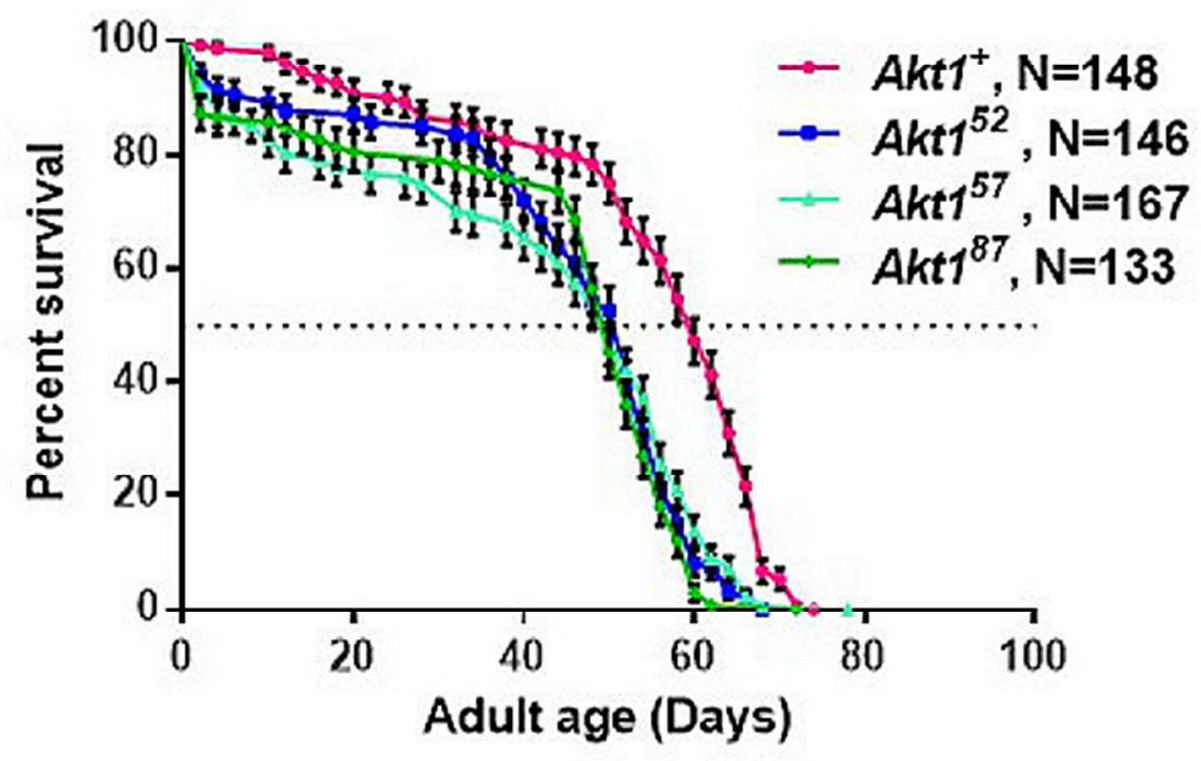

Figure 1: Longevity assay of novel Akt1 hypomorphs display a shortened lifespan when compared to controls.

$54 \times 39 \mathrm{~mm}$ (300 x 300 DPI) 
A

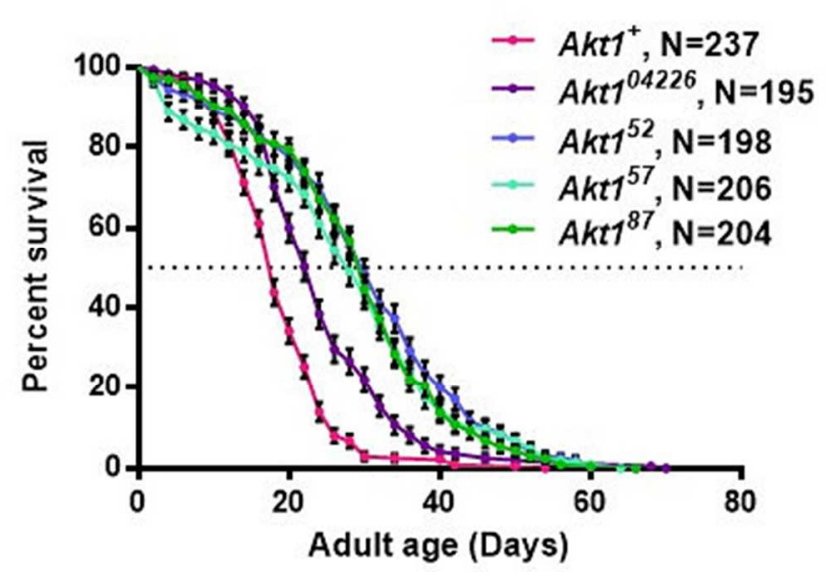

B

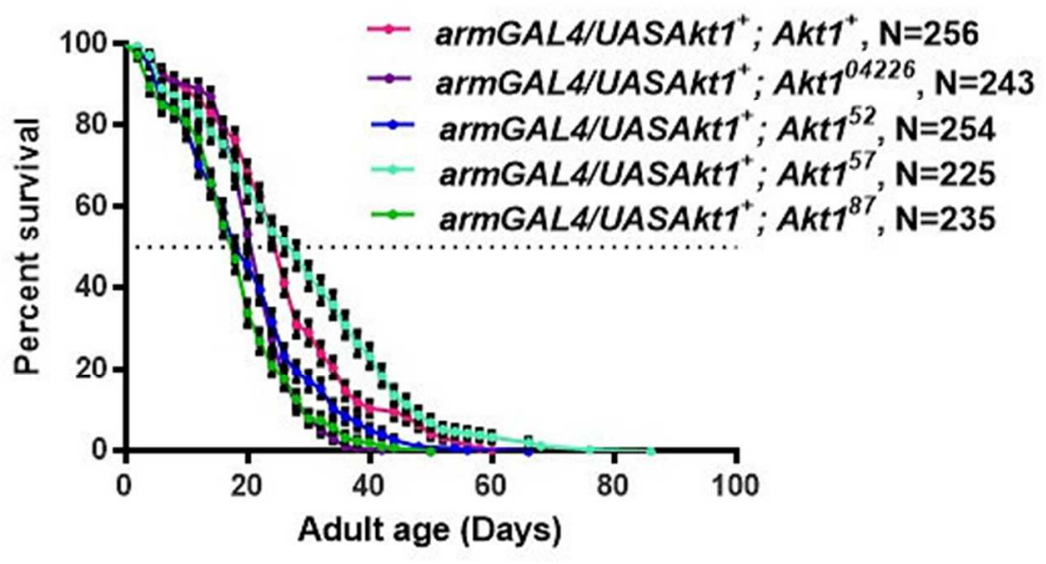

Figure 2: Amino-acid starvation survivorship assays of novel Akt1 hypomorphs indicate a long life phenotype that is suppressed when wild type Akt1 is expressed. $54 \times 57 \mathrm{~mm}(300 \times 300 \mathrm{DPI})$ 
A

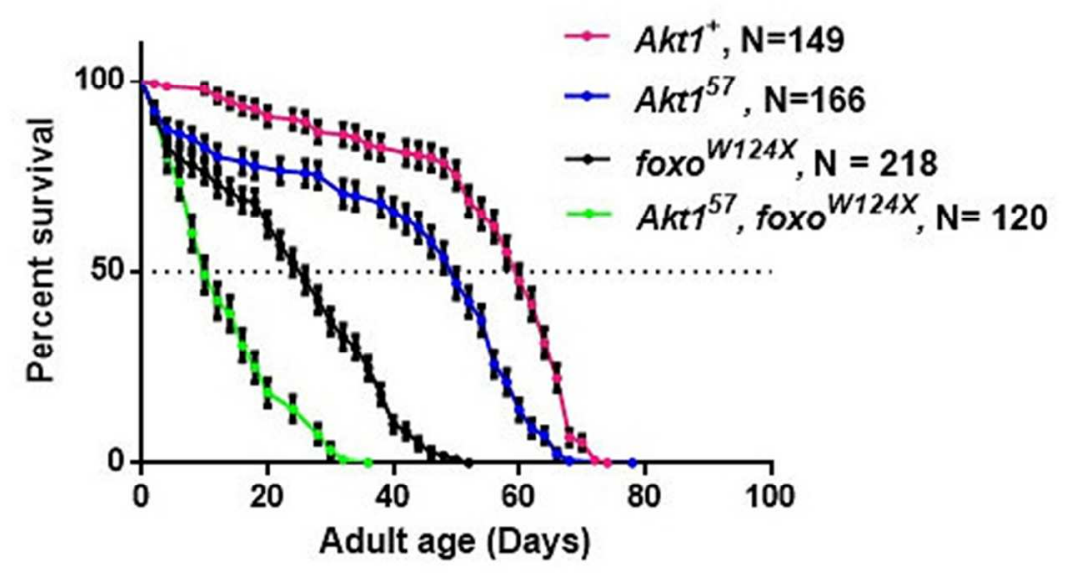

B

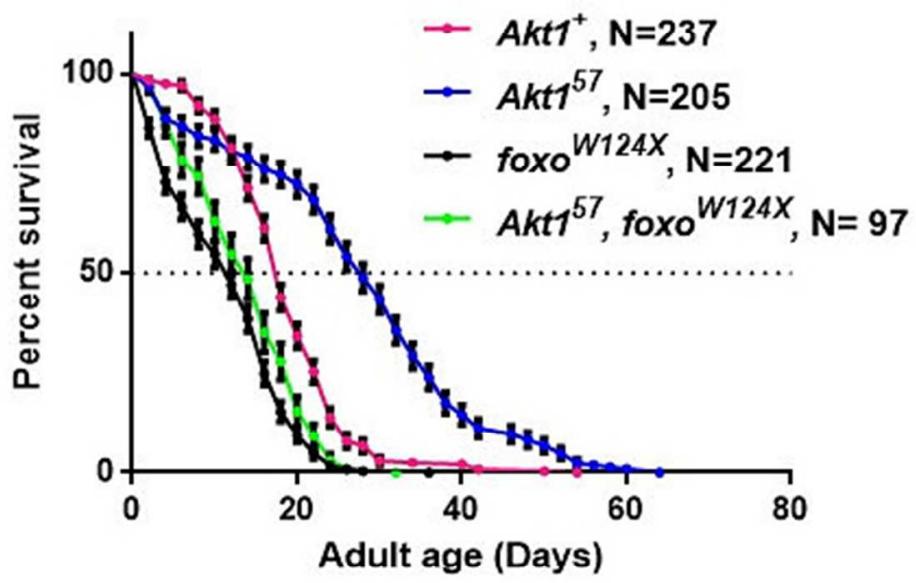

Figure 3: Longevity and amino-acid starvation survivorship assays of Drosophila bearing both novel Akt1 and a null foxo mutations: a synergistic effect upon standard media and an epistatic relationship when starved of amino-acids.

$50 \times 56 \mathrm{~mm}(300 \times 300$ DPI $)$ 